University of Nebraska - Lincoln

DigitalCommons@University of Nebraska - Lincoln

Faculty Publications, Department of Child, Youth, and Family Studies

Child, Youth, and Family Studies, Department of

August 2004

\title{
Chinese Adolescents' Decision-Making, Parent-Adolescent Communication and Relationships
}

\author{
Yan Ruth Xia \\ University of Nebraska-Lincoln, rxia2@unl.edu \\ Xiaolin Xie \\ University of Nebraska-Lincoln \\ Zhi Zhou \\ University of Nebraska-Lincoln \\ John Defrain \\ University of Nebraska-Lincoln, jdefrain1@unl.edu \\ William H. Meredith \\ University of Nebraska-Lincoln \\ See next page for additional authors
}

Follow this and additional works at: https://digitalcommons.unl.edu/famconfacpub

Part of the Family, Life Course, and Society Commons

Xia, Yan Ruth; Xie, Xiaolin; Zhou, Zhi; Defrain, John; Meredith, William H.; and Combs, Raedene, "Chinese Adolescents' Decision-Making, Parent-Adolescent Communication and Relationships" (2004). Faculty Publications, Department of Child, Youth, and Family Studies. 52.

https://digitalcommons.unl.edu/famconfacpub/52

This Article is brought to you for free and open access by the Child, Youth, and Family Studies, Department of at DigitalCommons@University of Nebraska - Lincoln. It has been accepted for inclusion in Faculty Publications, Department of Child, Youth, and Family Studies by an authorized administrator of DigitalCommons@University of Nebraska - Lincoln. 
Authors

Yan Ruth Xia, Xiaolin Xie, Zhi Zhou, John Defrain, William H. Meredith, and Raedene Combs 


\title{
Chinese Adolescents' Decision-Making, Parent-Adolescent Communication and Relationships
}

\author{
Yan R. Xia \\ Xiaolin Xie \\ Zhi Zhou \\ John DeFrain \\ William H. Meredith \\ Raedene Combs
}

\begin{abstract}
The present study described Mainland Chinese adolescents' decision-making, and examined the relationship among their decision-making involvement, parent-adolescent communication and relationship variables by using Structural Equation Modeling. Results demonstrated that Chinese parents appeared to be less authoritarian than the prevailing literature had described. Chinese adolescents experienced a passage of autonomy development similar to that of their American counterparts. Good parent-adolescent communication was positively associated with cohesion and negatively associated with conflict. It also mediated the relationship between adolescent age and parent-adolescent conflict. The
\end{abstract}

Yan R. Xia is affiliated with the University of Nebraska-Lincoln. Xiaolin Xie is affiliated with Northern Illinois University. Zhi Zhou is affiliated with First Data Corporation. John DeFrain is affiliated with the University of Nebraska-Lincoln. William H. Meredith is affiliated with Kansas State University. Raedene Combs is affiliated with the University of Nebraska-Lincoln.

Address correspondence to: Yan R. Xia, Family and Consumer Sciences, University of Nebraska-Lincoln (Omaha campus), 105c Ash 60th \& Dodge, Omaha, NE 68128-0214.

This paper is a contribution of the University of Nebraska Agricultural Research Division, Lincoln, NE 68583, Journal Series No. 13993.

http://www.haworthpress.com/web/MFR

(C) 2004 by The Haworth Press, Inc. All rights reserved.

Digital Object Identifier: 10.1300/J002v36n01_06 
relationships between parent-adolescent communication and cohesion as well as the relationship between adolescents' age and decision involvement were significantly different for boys and girls. [Article copies available for a fee from The Haworth Document Delivery Service: 1-800-HAWORTH. E-mail address: <docdelivery@haworthpress.com> Website: $<$ http://www.HaworthPress.com> (C) 2004 by The Haworth Press, Inc. All rights reserved.]

KEYWORDS. Chinese adolescents, decision-making, parent-adolescent communication, parent-adolescent relationships

\section{INTRODUCTION}

China has the world's largest youth population, but little is known about Chinese adolescents' involvement in decision-making in the family, the strength of parent-child relationships, and parent-adolescent communication. Chinese tradition places value on children's obedience to their parents (Ho, Sprinks, \& Yeung, 1989), with young people being discouraged from disagreeing and negotiating with their parents. Compared to Western societies, less emphasis is believed to be placed on the development of individual autonomy as a central task in adolescence.

With rapid economic development in China in the last two decades, however, this tradition has faced considerable challenge (Yau \& Smetana, 1996). In addition, the endorsement of the One Child Family Policy is believed to have influenced the manner in which parents raise their children (Xia, Lin, Xie, Zhou, \& DeFrain, 1998). This study is an effort to delineate current Chinese adolescent participation in the decision-making processes, and how this relates to parent-adolescent communication and adolescents' perceptions of their relationships with parents. The present study is unique in that it focuses on Mainland Chinese adolescents and uses decision-making processes as a key aspect of family interaction to examine associations among adolescents' decision-making, communication, and relationship.

\section{THEORETICAL PERSPECTIVE}

This study uses family systems theory and the ecological perspective as its theoretical framework. Adolescents grow through constant interactions with the family and the larger social systems. The implication of 
family systems theory for this study is to focus not only on the individuals that compose families but also on the patterns and interactions of family members. The ecological perspective (Bronfenbrenner \& Morris, 1998) provides a framework that allows examination of associations among adolescents' decision-making, parent-adolescent communication, and larger social contexts. The contexts include the familial, societal, and global environment, as well as the changes in these social environments due to their interaction and mutual influences. Studies of contemporary families that embrace a broad, multicultural perspective (Smith \& Ingoldsby, 1992) enable us to understand Chinese adolescents and their family relations that may well be affected by the outside changing world.

\section{LITERATURE REVIEW}

\section{Family and Adolescents' Decision-Making}

When family members make decisions, they operate within a shared system that governs the boundaries, role expectations, and the ways that they should interact with each other (Reiss, 1981). Family decisionmaking processes can be influenced by each member's role in the family, by their goals, values, and beliefs. Decision-making can be seen as a process of solving problems that result from the conflicts in obligation, expectation, and beliefs among family members. Decision-making in such a context needs to deal with the problem through integrating formerly opposed responsibilities and feelings, and modifying or transforming the relationships among the decision-makers (Diesing, 1962). Dornbusch, Ritter, Mont-Reynaund, and Chen (1990) found, in their study, that parents and adolescents might have different views of their roles in decision-making. Rettig noted, "These processes are often intensely emotional because of value and standard conflicts" (Rettig, 1993, p. 196).

Teenage children were found to have the greatest influence on deciding whether to buy the things that directly affected themselves, less on decisions about family vacations, and little on any other family matters (Belch, Geresino, \& Belch, 1985). Adolescents were expected to have more input as they grow older.

How much responsibility an adolescent can assume in decision-making is an indicator of parental recognition of the adolescent's competence, especially in decision-making and problem-solving. Involving 
adolescents in making decisions is viewed as a critical component that is indicative of how adolescents are parented, with the family decision-making style being reflective of the parenting style used. It is often assumed, for example, that authoritarian parents often grant their children little freedom for making decisions on their own, whereas permissive parents may grant children excessive autonomy without proper monitoring (Baumrind, 1967).

Past literature provides support for these assumptions. Adolescent involvement in decision-making processes was found to be associated with outcome behaviors. One study showed that violent adolescent children did not have as much input in decision-making processes as did normal functioning adolescents, after controlling for the influences of external family structure, e.g., divorce, desertion, family size, and so forth (Harbin \& Madden, 1983). However, excessive involvement in decision-making may not necessarily produce positive outcomes, especially for early adolescents. Individual autonomy in decision-making at too early an age was associated with low effort by adolescents in school and low school achievement. Lack of parental supervision and involvement in the younger youth's decision-making did not prompt them to excel at school (Dornbusch et al., 1990).

\section{Parent-Adolescent Relationships}

Studies of parent-child relationships during the adolescent period repeatedly show that the transition into adolescence accompanies some levels of tension between parents and their children, and disruption in the family (Collins \& Russell, 1991; Fuligni, 1998; Paikoff \& Brooks-Gunn, 1991). Parent-child conflict and emotional distancing are perceived predominantly as a function of the development of the adolescent's autonomy. Adolescents redefine their roles in decision-making that used to be their parents' domain, and seek an equalitarian parent-child relationship. The growing sense of autonomy and independence prompts adolescents to exercise more control over their activities, and to be more critical of their parents' values and beliefs. Conflicts occur when parents are reluctant to accommodate the change, and when there is not an agreement in role expectations between parents and children (Smetana, 1988). The level of conflict between parents and adolescents decreases after early or middle adolescence (Laursen \& Collins, 1994). A reasonable degree of independence and supportive parent-child relationship are seen to be the healthiest to adolescent development (Grotevant \& Cooper, 1985). Trou- 
bled relationships are reported more likely to occur between adjudicated adolescents and their parents (Smith \& Kerpelman, 2002).

The fact that conflict is often seen as a synonym for adolescence does not suggest that conflict only has negative implications for adolescent growth (Collins \& Laursen, 1992; Paikoff \& Brooks-Gunn, 1991; Peterson, Wilson, Bush, \& Zhao, 2002; Steinberg, 1990). Psychoanalytic theorists believe that conflict encourages individuation; developmental psychologists assert that conflict redefines interpersonal roles; and social exchange theorists suggest that conflict provides a context for monitoring the relationship between rewards and costs. They all believe conflict is important in fostering development (Laursen \& Koplas, 1995).

\section{Parent-Adolescent Communication and Interaction}

Good parent-adolescent relationships can hardly be sustained without open and healthy communication between parents and adolescent children. Parent-adolescent communication plays an essential role in family functioning throughout adolescence (Collins, 1990; Gecas \& Seff, 1990; Noller, 1994; Scabini, 1995; Sroufe, 1991; Youniss \& Smollar, 1985). Communication among family members is one of the most crucial facets of interpersonal relationships and the key to understanding the dynamics underlying family relations (Clark \& Shields, 1997). Within the family system, family members constantly define and adjust their relationships through patterns of communication (Watzlawick, Beavin, \& Johnson, 1967). Understanding communication patterns makes it possible to better understand cohesion, decision-making processes, and family rules and role expectations (Clark \& Shields, 1997).

Families with a good communication style help the adolescent develop a clearer sense of self (Barnes \& Olson, 1985). Effective communication at home helps clarify the role of adolescents within families and helps them develop the skill of empathy so that their personal identity effectively balances feelings of both individuality and connectedness (Grotevant \& Cooper, 1985). Good communication improves adolescents' social skills that are positively correlated with self-esteem, well-being, coping, and social support (Bijstra, Bosma, \& Jackson, 1994). Adequate communication between parents and adolescents (being able to freely express opinions and feelings) can effectively mediate the stress that adolescents experience. They will be less likely to feel lonely and suffocated in the external world when they know they are en- 
couraged, supported, and always have somebody to count on at home (Marta, 1997).

Communication facilitates the process of family cohesion and adaptability development. Good communication between parents and adolescent children leads to closer family relationships and helps them to be more loving and flexible in solving family problems (Barnes \& Olson, 1985). Open communication with parents has a strong positive correlation with family satisfaction (Jackson, Bijstra, Oostra, \& Bosma, 1998).

\section{Chinese Parent-Adolescent Communication and Relationships}

In traditional Chinese culture, nonconfrontational communication among people is valued in order to prevent them from losing face or dignity (Hong, 1989). Nonconfrontational communication refers to expressing one's thoughts and feelings in an indirect, and implicit manner, particularly when people disagree. This pattern of communication is evident among family members, not only to preserve an individual's dignity, but also to protect family harmony and family ties. Children are obligated to obey their parents and take care of them when the parents get old (filial piety), as their parents are obligated to nurture and raise them while the children grow up.

Most of the studies on current Chinese parent-adolescent relationships have been conducted in Hong Kong. Yau and Smetana (1996) examined adolescent-parent conflict in Hong Kong families of lower economic status. They reported that moderate conflicts were observed primarily between adolescents and mothers over daily issues of family life. Hong Kong adolescents wanted more independence in decision-making than the parents granted them. They perceived fathers as relatively less demanding, less concerned, more restrictive, and harsher than mothers, and adolescent girls perceived mothers as more demanding but less harsh (Shek, 1998; 1995). Hong Kong parents were perceived as moderately warm and relatively controlling. Other studies in Hong Kong showed that better relationships with parents were linked to higher self-concepts, better school performance, social skills, and physical ability, while poorer relationships with parents were reported to relate to more misconduct and delinquency, as well as more psychological symptoms (Lau \& Leung, 1992; Shek, 1997).

In comparison with Australian and American youth, Chinese adolescents in Hong Kong had expectations for independence at a later age, and put less emphasis on individualism (Feldman \& Rosenthal, 1991). However, a similar pattern of association with family environment was 
identified across the three groups. Expectations for later autonomy were related to adolescents' perceptions of parental monitoring, a demanding family environment, and authoritarian parents. Fuligni (1998) reported in his comparative study that Chinese American youth had later expectations for autonomy, and girls showed later expectations than boys across all ethnic groups, including Caucasian.

In studies conducted in China, Taiwan, and the U.S., researchers found that Chinese and Chinese-American parents appeared to be controlling, to encourage independence, and to emphasize achievement (Lin \& Fu, 1990; Peterson et al., 2002). These findings seemed contradictory to the prevailing literature about Chinese parents' views of children's autonomy development. To explain their findings, Lin and $\mathrm{Fu}$ pointed out, "A distinction should be made between family interdependence and individual independence. Although Chinese people tend to value interdependence and minimize the development of individuality within families, individual independence is not necessarily discouraged" (Xu, Shen, Wan, Li, Mussen, \& Cao, 1991, p. 432).

\section{Traditional Chinese Family Values}

Confucianism is the dominant philosophy that influences Chinese family values. Confucianism emphasizes social and family harmony, and family hierarchy (Ho, 1981; Hsu, 1985). The only way to achieve social harmony is to achieve family harmony by respecting family authority, namely, by conforming to and obeying people in authority. Chinese families are described as highly cohesive, partially due to a high cultural emphasis on harmony and mutual obligations and low value on overt expression of affection and disapproval. The families tend to suppress conflicts because obedience and respect for elders are valued (Liang, 1974). Even though China is undergoing rapid social change and westernization, filial piety remains one of the most important moral standards that guide the behaviors of family members and regulates the relationship between parents and older children (Goodwin \& Tang, 1996).

Few studies on adolescents' decision-making and parent-adolescent communication have focused on Chinese families in Mainland China. Research on the parent-adolescent relationship in a Chinese cultural context has been conducted in Chinese families in Hong Kong and Chinese-American families in the United States. Research is needed to understand the relationship between parents and adolescents in Mainland China.

Besides, Chinese families have been traditionally characterized as emphasizing absolute parental authority and valuing collective interest 
more than individual autonomy. Does this characterization of Chinese families still remain a fairly accurate picture of the current families on the mainland? If parent-adolescent relationships (i.e., cohesion and conflict) were a function of autonomy development, would it occur within Chinese families in which children are expected to obey their parents? If Chinese parent-adolescent communication were still marked by indirectness, would open communication exert an impact on the adolescents' relationships with their parents? This study was aimed at addressing the first question through describing how much Chinese adolescents were involved in decision-making processes, and the latter two questions through testing a theoretical model.

\section{METHODOLOGY}

\section{Sample}

Participants were students from the seventh to twelfth grade in two metropolitan high schools, and freshmen at a state university in Baoding, Hebei, P.R. China. Baoding is a middle-sized city by Chinese standards, with a population close to one million. It is approximately one hundred miles to the south of Beijing. The economic reform that began in 1978 has significantly improved living conditions. The city has a history dating back more than 2,300 years. Baoding residents are known for their longevity. The average life expectancy of 77.8 is 6.4 years longer than the nation's average lifespan in 2000 (Embassy of P.R. China in the U.S., 2002). Three schools in Baoding were contacted, and two schools agreed to participate.

All the enrolled students at the two high schools were invited to participate in the study. Eighth and ninth graders at one school were on a field trip and could not participate. The remaining students completed self-report questionnaires administered to them in class in the spring of 2000. A total of 660 students returned the questionnaire, and the response rate was $94 \%$. The questionnaires were also distributed at an English language class to college freshmen in the departments of biology and economics; 143 of these students responded, representing about $90 \%$ of first-year students in these two departments. In total, 803 students returned questionnaires, and 768 of these were regarded as valid for the study. The percentage of missing data is below $4 \%$.

Sixty-four percent of the participants were female and $34.2 \%$ were male. Their ages ranged from 12 to 19 with a mean of 16.19 and stan- 
dard deviation of 2.48. Among the total 768 adolescents, $83 \%$ came from nuclear families, $7.6 \%$ from extended families, $3.5 \%$ from single-parent families, $1 \%$ from stepfamilies, and $4.8 \%$ were living apart from their parents. Nearly $59 \%$ were the only children in the family, $33.7 \%$ had one sibling, and about $7.7 \%$ had two siblings. It is not clear why the only children accounted for only $59 \%$ of the total participants who were all born after the One Child Family Planning Policy was implemented in 1979. The first possible explanation could be that the policy was not strictly reinforced, in particular, in rural areas. One of the participating schools was a vocational school, which had some students from the families in the rural areas. Chinese farmers do not have pensions and usually rely on their children financially and physically in their old age. Because of that, the amendment to the One Child Family Planning Policy permits farmer families who have a daughter to petition to have another child. Second, the One Child Policy stipulates that minority families, and families with a disabled or chronically ill child could have more than one child.

Regarding parents' education, $53.8 \%$ of the mothers and $54.8 \%$ of the fathers of the adolescent participants had a high-school diploma. Fathers had a higher percentage of degrees than did mothers across all levels of education, but the discrepancy was not large. Fifteen percent of the fathers did not finish high school, while a little over $23 \%$ of the mothers did not finish high school. Overall, about $26 \%$ of the fathers had received an associate or higher degree, while $20 \%$ of the mothers had the same level of education.

\section{Measures}

Adolescent's Involvement in Decision-Making. Chinese adolescents' perceptions of their involvement in decision-making were measured by a self-report questionnaire developed by the researcher for this study. It consisted of 11 areas of decision-making on issues relevant to adolescents in the age range studied (e.g., hair style, clothes style, making friends, dating, curfew time, spending allowance, leisure activities, time of doing homework, going to college or not, choosing college major). The participants were asked to indicate who made most of the decisions (e.g., mother, father, yourself, all together). The raw score for adolescent's involvement in decision-making was computed by summing all the areas to which the adolescents perceived that they contributed most in making decisions. Then the raw score was weighted on the total number of the decisions relevant to adolescents. 
Parent-Adolescent Communication. The Parent-Adolescent Communication Scale was used to assess Chinese parent-adolescent communication (Olson, McCubbin, Barnes, Larsen, Muxen, \& Wilson, 1992). Each adolescent was asked to complete both The Adolescent and Mother Form and The Adolescent and Father Form of the Parent-Adolescent Communication Scale. The instrument is a 5-point Likert-type scale, and consists of 20 items of which 10 items measure each of two subscales (i.e., Open and Problems communication). The Open communication subscale includes items such as "I find it easy to discuss problems with my mother/father," "My mother/father is always a good listener," "If I were in trouble I could tell my mother/father," "My mother/ father can tell how I'm feeling without asking." The Problems communication subscale includes items such as "My mother/father has a tendency to say things to me which would be better left unsaid," "When we are having problems, I often give my mother/father the silent treatment," "I am sometimes afraid to ask my mother/father for what I want," "I'm careful about what I say to my mother/father" (Olson et al., 1992). The greater value of the raw scores indicates a higher degree of openness and more problems. For the current study, the two indicators for parent-adolescent communication factor are the total scores of each subscale. Prior to data analysis, raw scores on the Problems subscale are recoded with the greater value indicating fewer problems. Scores of both mother-adolescent and father-adolescent communication reported by the adolescent child were obtained for each adolescent.

The Parent-Adolescent Communication Scale demonstrates some construct validity when applied in different cultural contexts (Conoley, 1995). The internal consistency (Cronbach's Alpha) is .87 for the Openness subscale, .78 for the Problems subscale, and .88 for the total scale. The correlation (r) of test-retest is .78. The Cronbach's Alphas for these three scales with the present Chinese sample were $.84, .72$, and .84 for mothers, $.88, .76$, and .87 for fathers, and $.84, .72$, and .84 for the total sample, respectively.

\section{Parent-Adolescent Relationship}

The Chinese parent-adolescent relationship scale consisted of two subscales: cohesion and conflict. The 10-item cohesion subscale of the Family Adaptability and Cohesion Evaluation Scales (FACES II) was used to assess parent-adolescent cohesion, and the 5-item accord/conflict subscale of The Family Strengths Scale was used to assess parent-adolescent conflict (Olson et al., 1992). After an initial Confirmatory 
Factor Analysis with cohesion and conflict as latent variables, six indicators on the parent-adolescent relationship scale with factor loadings below .40 were dropped off. Five indicators for cohesion and four indicators for conflict were retained. The five cohesion indicators included supporting each other during difficult times, doing things together, feeling very close to each other, going along with what the family decided to do, and liking to spend free time together. The four conflict indicators included many conflicts, difficulty of accomplishing things, inability to solve the problem, and being critical of each other. The greater value of cohesion indicated higher cohesion, and the greater value of conflict indicated more conflicts. Cronbach's alphas for Cohesion, Adaptability, and Total Scale are .87, .78, and .90 for FACES II (Olson et al., 1992). FACES II is also reported having a correlation with other instruments measuring constructs similar to cohesion and adaptability (Hampson, Hulgus, \& Beavers, 1991). The Cronbach's Alphas with the present Chinese sample are .69 (cohesion), .68 (conflict), and .76 (total). The low internal consistency is acceptable as this study is exploratory.

\section{DEMOGRAPHIC INFORMATION}

Demographic information included family structure, parents' gender and education, and adolescents' age and gender. Parents' education was measured in ordinal form that consists of school, not finishing high school, finishing high school, having an associated degree, a Bachelor's degree, an MA/MS, or a $\mathrm{PhD}$. Measurement equivalency is an essential issue in such cross-cultural studies as the present one, which used scenario-based instrumentation outside of the country of origin. The back translation technique was used to reduce nonequivalent measurements in the instrument (Rose, 1985; Riordan \& Vandenberg, 1994). After one translator translated the questionnaire into Chinese, another bilingual person translated the Chinese version back into English. Then the two translators compared the original and translated English versions. If there was a discrepancy, adjustment followed when agreement was reached after discussion.

\section{DATA ANALYSIS}

Structural Equation Modeling (SEM) was employed to analyze the data in this study by using AMOS 4.0 (Arbuckle \& Wothke, 1999). A 
check on multivariate normality of the data showed the multivariate normality assumption was not seriously violated. Evidence suggests that the maximum likelihood method is reasonably robust to modest violation of the normality assumption (Hu \& Bentler, 1995). Maximum likelihood method was chosen as the method of estimation. The cut-off values of the fit indices for the present study are .95 for the Normed Fit Index (NFI), Tucker-Lewis Index/Non-Normed Fit Index (TLI/NNFI), and the Comparative Fit Index (CFI), and the Root Mean Square Error of Approximation (RMSEA) is lower than .08 (.05 indicates a close fit).

\section{The Measurement Model}

The overall measurement model for the present study consisted of four latent variables, two observed variables, and thirteen observed indicators. The latent variables were cohesion (5 indicators), conflict (4 indicators), communication ( 2 indicators), and parent education ( 2 indicators). One observed exogenous variable was adolescent age, and another observed variable, adolescent involvement in decision-making, was specified as both an exogenous and endogenous variable. This model was tested twice with the data of adolescent perceived communication with mother and father separately.

\section{The Structural Model}

The structural model was first tested without differentiating the group differences between boys and girls (see Figure 1). It was also tested twice with the data of adolescent perceived communication with mother and father separately. The following relationships were examined through testing the structural model:

1. Parent-adolescent communication and parent-adolescent cohesion;

2. Parent-adolescent communication and parent-adolescent conflict;

3. Age and parent-adolescent communication;

4. Age and parent-adolescent conflict;

5. Age and adolescent involvement in decision-making;

6. Adolescent involvement in decision-making and parent-adolescent cohesion;

7. Adolescent involvement in decision-making and parent-adolescent conflict; and

8. Parent education and adolescent involvement in decision-making. 
FIGURE 1. The Full Model

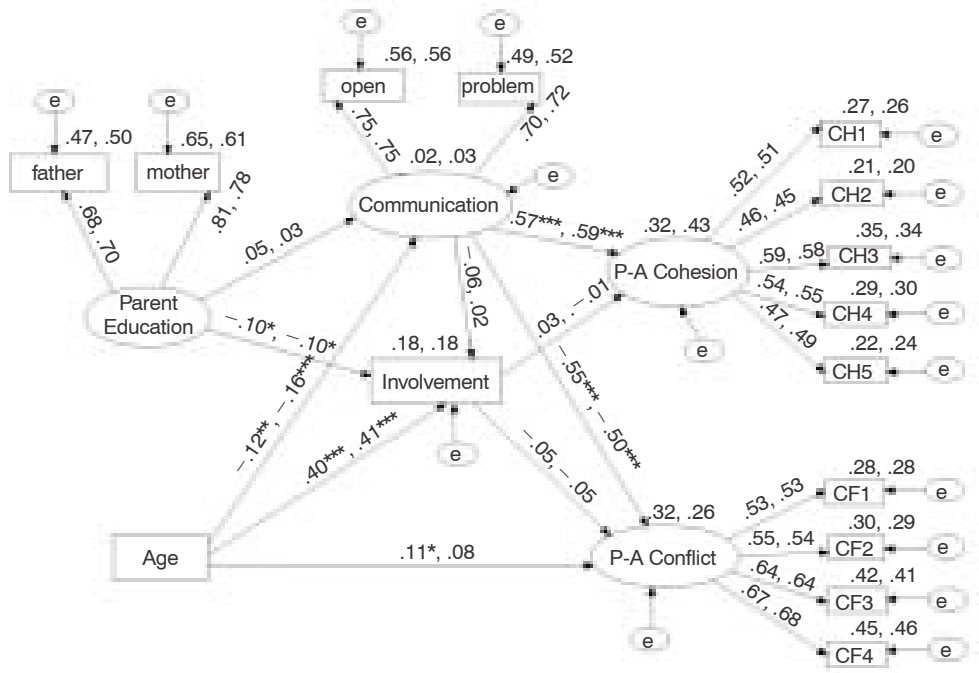

Note: The first set of parameter estimates is based on mother-adolescent communication, and the second set is based on father-adolescent communication.

All the factor loadings are significant at $p<.001$.

Parameter estimates above endogenous variables are R-squares.

Although a structural model was specified, cause-and-effect relationships cannot be inferred because all the data were collected at the same time.

Mediating Effects of Adolescents' Decision Involvement and Communication. The researchers followed the three criteria, suggested by Baron and Kenny (1986) which need to be met for a significant mediating effect: (1) the predictor is significantly linked to the criterion variable; (2) the predictor and the mediator are significantly associated; and (3) the mediator and criterion are significantly associated. They note that the mediating effect "accounts for the relations between the predictor and the criterion" (p. 1176), and explains how a significant relationship occurs. The structural model was specified in a way that allows the following mediating effects to be examined: the mediating effects of parent-adolescent communication on the age-conflict relationship, adolescents' involvement on the age-conflict relationship, and adolescents' involvement on the association of parent-adolescent communication and relationships (i.e., cohesion and conflict). 
Moderating Effect of Gender. A moderating effect exists when a significant relationship occurs depending on the condition specified by the moderator. In our study, there would be a moderating effect of gender if a significant path existed for one gender group but not for the other, or a path coefficient was significantly different between boys and girls. Multi-group analysis was used to test if each path coefficient in the adolescent boys' group was different from the corresponding coefficient in the girls' group. Prior to comparing the differences on the path coefficients between boys and girls, it was examined whether the factor loadings for latent variables differed significantly between the groups. If the latent variables were not defined consistently across the groups, the path coefficients from the structural model would not be comparable. This analysis was accomplished by testing three nested models: baseline/unconstrained, factor loading constrained, and factor loading and path coefficient constrained. Then a Chi-square difference test was done to determine whether the model with paths constrained was not significantly less fit than the less or unconstrained models.

\section{RESULTS}

\section{Adolescent Involvement in the Decision-Making Processes}

The adolescent participants were asked who made the decision in their families on issues such as curfew, making friends, dating, hair style, clothes, spending allowance, leisure activities, doing school assignment, and college education. Results demonstrated that the adolescent participants had the highest input in deciding when they should do their homework. Nearly $89 \%$ of them made this decision on their own. The next highest input in decision-making they had was over how to spend their allowance. The adolescents reported that they had least power in deciding how late they could stay out (31\%), and whether they could attend parties at night (25.4\%). Less than one-third of them indicated that they made decisions over these issues by themselves.

Parents made most joint decisions about their adolescent children over curfews (29.3\%), dating (27.1\%) and attending parties (34.6\%). Parents involved their adolescent children most in deciding the highest education degree their children should pursue (36.5\%), and the college major they should choose (34\%) by engaging them in making joint decisions. Mothers were most involved in making decisions over their children's 
clothing styles (20.1\%) and curfew time (19.1\%), while fathers were most involved in decisions over level of education and curfews.

\section{The Measurement Model}

Results of the Confirmatory Factor Analysis (CFA) indicated that the model fit both father-adolescent and mother-adolescent data well (for both sets of data: NFI, TLI/NNFI, and CFI = .99; Re: mother, $\chi^{2}[77]=$ $152.32, p<.01$; Re: father, $\left.\chi^{2}[77]=162.82, p<.01\right)$. RMSEA was .036 with RMSEALO $=.027$, RMSEAHI $=.044$, and PCLOSE $=.998$ for both models. The factor loadings of the 13 indicators ranged between .45 and .84 with $p<.001$. Correlation estimates among factors from the measurement model are presented in Table 1.

\section{The Structural Model}

The structural model was estimated twice using the data of father-adolescent communication and mother-adolescent communication, respectively. Results indicated that the model fit both data well (for both sets of data: NFI, NNFI/TLI, and CFI $=.99$; Re: mother, $\chi^{2}[82]=$ $179.24, p<.05, \chi^{2} / \mathrm{df}=2.2 ; \mathrm{Re}$ : father, $\chi^{2}[82]=189.95, p<.05, \chi^{2} / \mathrm{df}=$ 2.3). RMSEA was .034 with RMSEALO $=.028$, RMSEAHI $=.040$, and PCLOSE $=1.000$ for the mother's model, and RMSEA was .032 with RMSEALO $=.026$, RMSEAHI $=.038$, and PCLOSE $=1.000$ for the fa-

TABLE 1. Correlation Estimates from the Measurement Model

\begin{tabular}{lcccccc}
\hline & Conflict & Cohesion & Communication & Education & Age & Involvement \\
\hline & & & & & & \\
Conflict & -- & $-.25^{\star \star \star}$ & $-.57^{\star \star \star}$ & -.06 & $.14^{\star \star \star}$ & .01 \\
Cohesion & $-.25^{\star \star \star}$ & -- & $.58^{\star \star \star}$ & .10 & -.08 & -.04 \\
Communication & $-.52^{\star \star \star}$ & $.60^{\star \star \star}$ & -- & .06 & $-.13^{\star \star}$ & $-.11^{\star \star}$ \\
Education & -.04 & .09 & .01 & -- & $-.20^{\star \star \star}$ & $-.18^{\star \star \star}$ \\
Age & $.14^{\star \star \star}$ & -.06 & $-.18^{\star \star \star}$ & $-.20^{\star \star \star}$ & -- & $.41^{\star \star \star}$ \\
Involvement & .01 & -.04 & -.06 & $-.18^{\star \star \star}$ & $.42^{\star \star \star}$ & -- \\
\hline
\end{tabular}

Note: The communication in the upper diagonal is father-adolescent communication, and that in the lower diagonal is mother-adolescent communication.

** $p<.01,{ }^{\star \star \star} p<.001$. 
ther's model. The factor loadings of all the indicators were statistically significant at $p<.001$ (see Figure 1).

Relationships Among the Constructs and Variables. The structural parameter estimates-path coefficients from the model with mother-adolescent communication and the model with father-adolescent communication are presented in Figure 1. Results indicated that as adolescents were growing older, father- or mother-adolescent communication became less open and more problematic, and mother-adolescent relationship experienced more conflict. Adolescent age was a strong predictor of decision involvement. Parents' education was not observed to have a significant link to parent-adolescent communication. Better mother-adolescent communication was observed to be strongly associated with higher cohesion and less conflict. The more adolescents were involved in decision-making, the less conflict between mother and son or daughter. Father-adolescent communication was found to be a strong predictor of cohesion and conflict as was mother-adolescent communication.

Mediating Effects. Both father- and mother-adolescent communication had a significant mediating effect on the relationship between age and conflict. The older the adolescent was, the poorer parent-adolescent communication (Re: father, $\gamma=-.16, \mathrm{p}<.001$; Re: mother, $\gamma=-.12$, $\mathrm{p}<.01)$. In turn, the poorer parent-adolescent communication, the more conflict there was between parents and adolescent children (Re: father, $\gamma=-.50, \mathrm{p}<.001$; Re: mother, $\gamma=-.55, \mathrm{p}<.001)$. No significant path coefficients were observed from either father- or mother-adolescent communication to decision involvement (Re: father, $\gamma=.02, p>.10$; Re: mother, $\gamma=-.06, \mathrm{p}>.10)$. Nor were the paths from decision involvement to cohesion (Re: father, $\gamma=-.01, \mathrm{p}>.05$; Re: mother, $\gamma=.03$, $\mathrm{p}>.10$ ). Therefore, decision involvement did not have any mediating effect on the relationship between parent-adolescent communication and cohesion. Decision involvement was observed to have a mediating effect on the relationship between age and conflict in the model with mother communication data. More involvement of older adolescent in decision-making appeared to decrease parent-adolescent conflict (age-involvement: $\gamma=.40, \mathrm{p}<.001$; involvement-conflict: $\gamma=-.09, \mathrm{p}<.05)$.

The Moderating Effect of Gender. Multi-group analysis was conducted to examine the moderating effect of gender. In addition to the unconstrained model (baseline model), two constrained models were tested in sequence. The first was a model with each factor loading set to 
be equal between the groups of boys and girls, but with error variances and path coefficients free. The second was a model with invariant factor loadings and path coefficients. The fit indexes for the nested models are presented in Table 2.

Compared to the baseline model, the model with constrained factor loadings had $\Delta \chi^{2}(\Delta \mathrm{df})=6.57(9), p>.10$ for mother-adolescent communication data, and had $\Delta \chi^{2}(\Delta \mathrm{df})=6.12(9), p>.10$ for the father-adolescent communication data, indicating the constrained model did not appear to be significantly less fit than the unconstrained one. Therefore, the latent variables are not defined differently across the gender groups. Further comparison between the models with only factor loadings constrained and with both factor loading and path coefficients constrained revealed a significant Chi-square reduction in the model with motheradolescent communication data $\left(\Delta \chi^{2}(\Delta \mathrm{df})=23.39(10), p<.01\right)$, but not with father-adolescent communication data $\left(\Delta \chi^{2}(\Delta \mathrm{df})=10.02(10), p>\right.$ $.05)$. The results indicated that there was a moderating effect of gender. Inspection of critical ratios for parameter differences showed that the path coefficients from mother-adolescent communication to cohesion

TABLE 2. Fit Indices for Nested Models in Multi-Group Analysis

\begin{tabular}{|c|c|c|c|c|c|c|c|}
\hline Model & $x^{2}$ & $\mathrm{NFI}$ & NNFI & CFI & $\Delta \mathrm{X}^{2}$ & $\Delta \mathrm{df}$ & $\Delta \mathrm{NFI}$ \\
\hline \multicolumn{8}{|l|}{ Re: mother } \\
\hline 1. Baseline/free parameters & 306.20 & .989 & .992 & .995 & & & \\
\hline 2. Constrained factor loadings & 312.77 & .989 & .993 & .995 & & & \\
\hline Model 2 \& Model 1 & & & & & 6.57 & 9 & .000 \\
\hline $\begin{array}{l}\text { 3. Constrained factor loadings \& } \\
\text { path coefficients }\end{array}$ & 336.06 & .988 & .993 & .995 & & & \\
\hline Model 3 \& Model 2 & & & & & $23.29 * \star$ & 10 & .001 \\
\hline \multicolumn{8}{|l|}{ Re: father } \\
\hline 1. Baseline/free parameters & 291.84 & .989 & .993 & .995 & & & \\
\hline 2. Constrained factor loadings & 297.96 & .989 & .994 & .995 & & & \\
\hline Model 2 \& Model 1 & & & & & 6.12 & 9 & .000 \\
\hline \multirow{2}{*}{$\begin{array}{l}\text { 3. Constrained factor I } \\
\text { path coefficients } \\
\text { Model } 3 \text { \& Model } 2\end{array}$} & 308.18 & .989 & .994 & .995 & & & \\
\hline & & & & & 10.02 & 10 & .000 \\
\hline
\end{tabular}

Note: NFI = Normed Fit Index, TLI/NNFI = Tucker-Lewis Index/Non-Normed Fit Index, and $\mathrm{CFI}=$ Comparative Fit Index. ${ }^{* \star} p<.01$ 
and conflict were significantly different between the gender groups (for cohesion, $\mathrm{t}=2.33, p<.05$; for conflict, $\mathrm{t}=3.27, p<.01)$. Gender also accounts for the associations between adolescent age and decision involvement $(\mathrm{t}=-2.05, p<.05)$, age and father-adolescent communication $(\mathrm{t}=-10.07, p<.001)$, and father-adolescent communication and cohesion $(\mathrm{t}=7.74, p<.001)$.

\section{DISCUSSION}

\section{Chinese Adolescents' Involvement in Decision-Making}

In literature, Chinese parents are often reported as controlling and authoritarian (Ho, 1981; Shek, 1999, 2000), and Chinese teenagers are not believed to have much autonomy. The results from this study seem to suggest that present Chinese parents listen more to their children than has been previously believed. Counting the input that Chinese adolescents made in joint decisions with parents, the percentage of adolescent involvement in making decisions over the 11 issues ranged from $44.3 \%$ to $90.5 \%$. Over $60 \%$ of the adolescents reported that they had input in decisions in 9 out of 11 issues surveyed in this study. Chinese teenagers seemed to be most likely either to decide by themselves or to have some input in the decisions about issues like making friends, going for entertainment, choosing a college major, doing homework, and having an allowance. Chinese parents appeared to retain their power over issues like curfews and attending parties. Parents and children made most joint decisions on children's education, such as choosing a college major and pursuing higher education. These results showed that the Chinese parent participants allowed their children to have input into decision-making, and the majority of them made shared decisions with their children. The finding seems to shed some new light on the parenting style of contemporary Mainland Chinese parents. The information gained from the present survey questions the popular image of authoritarian Chinese parents who have absolute power over their children. It supports the research findings from Lin and $\mathrm{Fu}$ (1990), and from Xu and his colleagues (1991) that Chinese parents may encourage both individuation and family connection.

This empirical data may suggest that the authoritarian Chinese parent is not an accurate stereotype or/and there is a change in Chinese parenting style. Allowing children to make decisions on their own shows parents' recognition of children as an individual rather than their possessions. A recent study documents that Chinese parents' values of raising children has shifted from emphasizing filial piety and obedience 
to emotional satisfaction (Xia et al., 1998). All the adolescent participants of this present study were born after 1979, the year when the One Child Family Planning Policy was implemented. Only children are frequently referred to as "little emperor or empress" in the media as well as by the public. These are the children who get away with unacceptable behaviors at home, and whose parents surrender their leadership in the family. Chinese parents are observed to be more doting, and more involved when choice of births is limited (Fablo \& Boston, 1994; Guo, 2001). The less controlling image of Chinese parents may mirror the impact of One Child Family Planning Policy upon Chinese parenting style.

The present study has found that adolescents' decision-making is strongly age-related. This finding is consistent with results from studies in Western cultural environments (Bosma, Jackson, Zijsling, Zani, Cicognani, Xerri, Honess, \& Charman, 1996; Liprie, 1993). Adolescents enjoy more power of decision-making as they grow older. The study does not reveal a significant link between adolescents' decision involvement and high family cohesion and good parent-adolescent communication, although a weak relationship between communication and decision-making is reported in another study that also uses the Parent-Adolescent Communication Scale (Jackson et al., 1998). However, less involvement is significantly related to more parent-adolescent conflict. The detected linkage to conflict is in agreement with findings reported by Australian researchers (Brown \& Mann, 1990), and supports that conflicts occur when adolescents want more independence in decision-making than their parents grant. It shows that Chinese adolescents experience the same passage of autonomy development as their Australian counterparts. As to why significant associations of adolescent involvement with parent-child cohesion and communication were not detected in this sample, one explanation may be that the adolescent decision-making involvement in this study was more a measure of frequency of making decisions rather than competence in decisionmaking. Good decision-making and communication skills can enhance each other and foster cohesion. Further research should examine the relationships between adolescent competence in decision-making and parent-adolescent communication and relationships.

\section{Parent-Adolescent Communication and Parent-Adolescent Relationships}

The present study has observed a strong positive link from parent-adolescent communication to parent-adolescent cohesion, and a strong 
negative link to parent-adolescent conflicts. This finding adds to the existing literature that positive parent-adolescent communication leads to closer family relationships, helping them to be more loving and flexible in solving family problems.

Parent-adolescent conflict and emotional distancing are documented repeatedly as a function of the development of adolescents' autonomy in Western studies (Fuligni, 1998; Collins \& Russell, 1991; Paikoff \& Brooks-Gunn, 1991). Results from the present study demonstrate the distancing effect of autonomy development of Chinese adolescents. The results may imply that Chinese adolescents go through a similar passage of struggle for autonomy and transformation of their communications and relationships with their parents as their American counterparts.

The present study has also found that positive mother-adolescent communication may reduce the conflicts that occur as adolescent children are growing up. Good parent-adolescent communication improves adolescents' social skills that lead to not only closeness in the parent-adolescent relationship, but also positive psychological outcomes such as high self-esteem, adequate coping and social support network (Bijstra et al., 1994). Other positive outcomes of family support and adequate communication are adolescents' individual and social adjustment and absence of deviant or delinquent attitudes (Hess, 1995; Marta, 1997; Noller, 1994), and the reduced risk of youth substance abuse and other delinquent behaviors (Clark \& Shields, 1997; Hirschi, 1969; Kafka \& London, 1991). Although the present study does not test the association of parent-adolescent relationships and communication with the physical and psychological outcomes of Chinese adolescents, the findings from research in Hong Kong and the U.S. have shown that parent-adolescent communication plays an essential role in this relationship (Lau \& Leung, 1992; Shek, 1997; Smith \& Kerpelman, 2002).

\section{Gender Differences}

The significant differences in the direct effect of age on involvement indicated that Chinese adolescent age is related differently to boys and girls in their involvement in decision-making. Age is a less strong predictor for adolescent girls' involvement than for adolescent boys'. That is, for both Chinese adolescent boys and girls, the older they are, the more involved they are. Furthermore, boys are more likely than girls to be involved if they are of the same age. Fuligni's (1998) study reported that Chinese American girls had a later expectation for autonomy. This 
may explain why the variable girls' age in this study was not linked to girls' involvement in decision-making as strong as was boys' age linked to boys' involvement. Moreover, Chinese males are expected to play a more active role in making family decisions than Chinese females (Ho, 1989). The different role expectations for boys and girls in Chinese culture may also explain this gender difference.

Chinese adolescent girls studied in this research report increased conflicts with parents but this is not the case for boys. The present finding is different from the literature in the U.S indicating that both American adolescent boys and girls experience increased conflicts with parents as they age (Collins \& Russell, 1991; Laursen \& Collins, 1994; Steinberg, 1990). This suggests that Chinese parents may be more controlling of daughters and may not negotiate with them as much as commonly occurs with sons. It may also reflect the girls' increasing voice of seeking autonomy.

Adolescent boys and girls are differently related to their fathers in both Western and Chinese cultures (Marta, 1997; Noller \& Callan, 1991; Shek, 1999, 2000; Youniss \& Smollar, 1985). Communication between Chinese fathers and mothers and adolescents appear to be associated strongly with parent-adolescent cohesion and conflict. For both boys and girls, the more open and less demeaning communication they have with parents, the closer they feel to their parents. In addition, girls were more likely than boys to experience a closer and less conflicting relationships with their parents when daughters and sons communicate equally well with them. When compared with girls, boys have a less open and more negative communication with their fathers when they are of the same age. The difference is not evident in adolescent-mother communication. Cultural factors may explain this difference. "A man should drop blood rather than tears" is a popular saying in Chinese culture (Shek, 2000). Males are not socialized with emotion and are not encouraged to talk about feelings. Mothers are regarded by most teens, particularly girls, as more understanding and accepting. Fathers are generally seen as more judgmental, authoritarian, and less willing to discuss emotional or personal issues (Youniss \& Smollar, 1985). This may also explain why fathers are not as responsive as mothers to their children's emotional needs and why adolescents go to mothers more than fathers for emotional comfort.

A strength of the present study is the use of Structural Equation Modeling. The advantage of this approach is that the inclusion of measurement errors as explicit parameters in a model allows reliability of 
variables to be estimated. When measurement errors are taken into account in the analysis, there is an increased "probability of detecting association and obtaining estimates of free parameters close to their population values" (Hoyle, 1995, p. 14). The present study is unique in that it has provided new literature on Mainland Chinese adolescents' decision-making process, and its association with parent-adolescent communication and relationships.

\section{Future Directions}

The differences in levels of development in economy and social reform may have an impact on the results of the study. People from more developed areas may have different beliefs and values about parenting, family relationship, and family communication when compared to those from less developed areas. Families from rural areas may have different values from those from urban areas. Children from nuclear families may be expected to participate differently in the decision-making processes from those from extended families, stepfamilies, or single-parent families. Small, rural, and inland areas are not as well developed as large, urban and coastal areas, with the result being that traditional values may be retained. The results of this study may be limited by the nature of its sample, and future studies should acquire samples that are more representative in terms of location, family structure, and social economic status. Another limitation of the study is that it only examines parent-adolescent communication and relationship variables perceived by adolescents. Parents' perspectives should be included in the future investigation.

\section{Applied Implications}

Parent-adolescent communication patterns have demonstrated relationships with parent-adolescent relationships, family functioning, youth's self-esteem, depression, competence in decision-making, school performance, and delinquent behaviors in American populations. The findings from this study have significant implications for practice in China where parenting or communication skills training has not been a common practice of prevention or intervention. Programs that are created to help Chinese parents and adolescents develop communication and problem-solving skills may not only help parents with parenting skills, but may also help adolescents become capable of making responsible choices, develop confidence and competence in making decisions, gain 
self-esteem, and stay free from high-risk behaviors. The results of this study point to the need for the implementation of family life education and programs of communication and problem-solving skills training in China.

\section{REFERENCES}

Arbuckle, J. L., \& Wothke, W. (1999). AMOS 4.0 user's guide. Chicago, IL: SmallWaters Corporation.

Barnes, H. L., \& Olson, D. H. (1985). Parent-adolescent communication and the circumplex model. Child Development, 56, 438-447.

Baron, R. M., \& Kenny, D. A. (1986). The moderator-mediator variable distinction in social psychological research: Conceptual, strategic, and statistical considerations. Journal of Personality and Social Psychology, 51(6), 1173-1182.

Baumrind, D. (1967). Childcare practices anteceding three patterns of preschool behavior. Genetic Psychology Monograph, 75, 43-88.

Belch, G. E., Geresino, G., \& Belch, M. A. (1985). Parental and teenager child influences in family decision-making. Journal of Business Research, 13, 163-176.

Bijstra, J. O., Bosma, H. A., \& Jackson, A. E. (1994). The relationship between social skills and psychosocial functioning in early adolescence. Personality and Individual Differences, 16, 767-776.

Bosma, H. A., Jackson, S., Zijsling, D. H., Zani, B., Cicognani, E., Xerri, M. L., Honess, T. M., \& Charman, L. (1996). Who has the final say? Decisions on adolescent behavior within the family. Journal of Adolescence, 19, 277-291.

Bronfenbrenner, U., \& Morris, P. A. (1998). The ecology of developmental processes. In W. Damon (Series Ed.) \& R. M. Lerner (Vol. Ed.), Handbook of child psychology: Vol. 1. Theoretical models of human development (5th ed., pp. 993-1028). New York: Wiley.

Brown, J. E., \& Mann, L. (1990). The relationship between family structure and process variables and adolescent decision-making. Journal of Adolescence, 13, 25-37.

Clark, R. D., \& Shields, G. (1997). Family communication and delinquency. Adolescence, 32(125), 81-92.

Collins, W. A. (1990). Parent-child relationships in the transition to adolescence: Continuity and change in interaction, affect, and cognition. In R. Montemayor, G. R. Adams, \& P. Gullotta (Eds.), Advances in adolescent development: Vol. 2. From childhood to adolescence: A transitional period? (pp. 85-106). Newbury Park, CA: Sage.

Collins, W. A., \& Laursen, B. (1992). Conflict and relationships during adolescence. In C. U. Shantz \& W. W. Hartup, (Eds.), Conflict in child and adolescent development (pp. 216-241). New York: Cambridge University Press.

Collins, W. A., \& Russell, G. (1991). Mother-child and father-child relationships in middle childhood and adolescence: A developmental analysis. Developmental Review, 11, 99-136. 
Conoley, J. C. (1995). Multicultural family assessment. In J. C. Conoley \& E. B. Werth (Eds.), Family assessment (pp. 103-129). Lincoln, NE: Buros Institute of Mental Measurements.

Diesing, P. (1962). Reason in society: Five types of decisions and their social conditions. Westport, CT: Greenwood Press.

Dornbusch, S. M., Ritter, P. L., Mont-Reynaund, R., \& Chen, Z. Y. (1990). Family decision-making and academic performance in a diverse high school population. Journal of Adolescent Research, 5(2), 143-160.

Embassy of P.R. China in the United States. (2002, September 17). Changes of Chinese people's lives: Facts and figures (No. 0217). Retrieved October 28, 2002, from http://www.china.org/eng/35247.html.

Fablo, T., \& Boston, Jr., D. L. (1994). The academic, personality, and physical outcome of only children in China. Child Development, 64(1), 18-35.

Feldman, S. S., \& Rosenthal, D. A. (1991). Age expectations of behavioral autonomy in Hong Kong Australian and American youth: The influence of family variables and adolescents' values. International Journal of Psychology, 26(1), 1-23.

Fuligni, A. J. (1998). Authority, autonomy, and parent-adolescent conflict and cohesion: A study of adolescents from Mexican, Chinese, Filipino, and European backgrounds. Developmental Psychology, 34(4), 782-792.

Gecas, V., \& Seff, M. A. (1990). Families and adolescents: A review of the 1980s. Journal of Marriage and the Family, 52, 941-958.

Goodwin, R., \& Tang, C. (1996). Chinese personal relationships. In M. H. Bond (Ed.), The handbook of Chinese psychology (pp. 294-308). Hong Kong: Oxford University Press.

Grotevant, H. D., \& Cooper, C. R. (1985). Patterns of interaction in family relationships and the development of identity exploration in adolescence. Child Development, 56, 415-428.

Guo, H. (2001). The "little emperors grow up." Psychology Today, 33, 10.

Hampson, R. B., Hulgus, Y. F., \& Beavers, W. R. (1991). Comparison of self-report measures of the Beavers Systems Model and Olson's Circumplex Model. Journal of Family Psychology, 4(3), 326-340.

Harbin, H. T., \& Madden, D. J. (1983). Assaultive adolescents: Family decision-making parameters. Family Process, 22, 109-118.

Hess, L. (1995). Changing family patterns in West Europe: Opportunities and risk factors for adolescent development. In M. Rutter \& D. Smith (Eds.), Psychosocial disorder in young people (pp. 104-119). Chichester: Wiley.

Hirschi, T. (1969). Causes of delinquency. Berkeley, CA: University of California Press.

Ho, D. Y. F. (1981). Traditional patterns of socialization in Chinese society. Acta Psychologica Taiwanica, 23, 81-95.

Ho, D. Y. F., Spinks, J. A., \& Yeung, C. S. H. (Eds.). (1989). Chinese patterns of behavior: A sourcebook of psychological and psychiatric studies. New York: Praeger.

Hong, G. K. (1989). An application of cultural and environmental issues in family therapy with immigrant Chinese Americans. Journal of Strategic and Systemic Therapies, 8, 14-21. 
Hoyle, R. H. (1995). Structural equation modeling: Concepts, issues, and applications. Thousand Oaks: Sage.

Hsu, J. (1985). The Chinese family: Relations, problems and therapy. In W. Tseng \& D. Y. H. Wu (Eds.), Chinese culture and mental health (pp. 95-112). Orlando, FL: Academic Press.

Hu, L., \& Bentler, P. M. (1995). Evaluating model fit. In R. H. Hoyle (Ed.), Structural equation modeling: Concepts, issues, and applications (pp. 76-99). Thousand Oaks: Sage.

Jackson, S., Bijstra, J., Oostra, L., \& Bosma, H. (1998). Adolescents' perceptions of communication with parents relative to specific aspects of relationships with parents and personal development. Journal of Adolescence, 21, 305-322.

Kafka, R. R., \& London, P. (1991). Communication in relationships and adolescent substance use: The influence of parents and friends. Adolescence, 26(103), 587-598.

Lau, S., \& Leung, K. (1992). Relations with parents and school and Chinese adolescents' self-concept, delinquency, and academic performance. British Journal of Educational Psychology, 62, 193-202.

Laursen, B., \& Collins, W. A. (1994). Interpersonal conflict during adolescence. Psychological Bulletin, 115(2), 197-209.

Laursen, B., \& Koplas, A. L. (1995). What's important about important conflicts? Adolescents' perceptions of daily disagreements. Merrill-Palmer Quarterly, 41(4), 536-553.

Liang, S. M. (1974). The essential features of Chinese culture. Hong Kong: Chi-Cheng T'u-Shu Kung Shu.

Lin, C. Y. C., \& Fu, V. R. (1990). A comparison of child rearing practices among Chinese, immigrant Chinese, and Caucasian-American parents. Child Development, 61, 429-433.

Liprie, M. L. (1993). Adolescents' contributions to family decision-making. Marriage \& Family Review, 18(3/4), 241-253.

Marta, E. (1997). Parent-adolescent interactions and psychosocial risk in adolescents: An analysis of communication, support and gender. Journal of Adolescence, 20, 473-487.

Noller, P. (1994). Relationships with parents in adolescence: Process and outcome. In R. Montemayor, G. Adams, \& T. Gullotta (Eds.), Personal relationships during adolescence (pp. 37-77). London: Sage.

Noller, P., \& Callan, V. (1991). The adolescent in the family. London: Routledge.

Olson, D. H., McCubbin, H. I., Barnes, H., Larsen, A., Muxen, M., \& Wilson, M. (1992). Family inventories (2nd revision). St Paul, MN: Family Social Science, University of Minnesota.

Paikoff, R. L., \& Brooks-Gunn, J. (1991). Do parent-child relationships change during puberty? Psychological Bulletin, 110(1), 47-66.

Peterson, G. W., Wilson, S. M., Bush, K. R., \& Zhao, B. (2002). Strengths in the Chinese parent-adolescent relationship: Socializing adolescent self-esteem and prosocial behavior. Presentation at the International Family Strengths Conference, Shanghai, P.R. China. 
Reiss, D. (1981). The family's construction of reality. Cambridge, MA: Harvard University Press.

Rettig, K. D. (1993). Problem solving and decision-making as central processes of family life: An ecological framework for family relations and family resource management. Marriage \& Family Review, 18(3/4), 187-222.

Riordan, C. M., \& Vandenberg, R. J. (1994). A central question in cross-cultural research: Do employees of different cultures interpret work-related measures in an equivalent manner? Journal of Management, 20, 643-671.

Rose, M. G. (1985). Back-translating to recover form. International Journal of Translation, 31(1), 6-11.

Scabini, E. (1995). Psicologia sociale della famiglia [The social psychology of the family]. Torino: Bollati Boringhieri.

Shek, D. T. L. (1995). Chinese adolescents' perceptions of parenting styles of fathers and mothers. The Journal of Genetic Psychology, 156(2), 175-190.

Shek, D. T. L. (1997). The relation of family functioning to adolescent psychological well-being, school adjustment, and problem behavior. The Journal of Genetic Psychology, 158(4), 467-479.

Shek, D. T. L. (1998). Adolescents' perceptions of parental and maternal parenting styles in a Chinese context. The Journal of Psychology, 132(5), 527-537.

Shek, D. T. L. (1999). Paternal and maternal influences on the psychological well-being of Chinese adolescents. Genetic, Social \& General Psychology Monographs, 125, 269-296.

Shek, D. T. L. (2000). Differences between fathers and mothers in the treatment of, and relationship with, their teenage children: Perceptions of Chinese adolescents. Adolescence, $35,135-144$.

Smetana, J. G. (1988). Concepts of self and social convention: Adolescents and parents' reasoning about hypothetical and actual family conflicts. In M. R. Gunnar \& W. A. Collins (Eds.), Minnesota symposia on child psychology (Vol. 21, pp. 79122). Hillsdale, NJ: Erlbaum.

Smith, S., \& Ingoldsby, B. (1992). Multicultural family studies: Educating students for diversity. Family Relations, 41(1), 25-30.

Smith, S. L., \& Kerpelman, J. L. (2002). Adjudicated adolescent girls and their mothers: Examining relationship quality and communication styles. Journal of Addictions to Offender Counseling, 23, 15-29.

Sroufe, J. W. (1991). Assessment of parent-adolescent relationships: Implications for adolescent development. Journal of Family Psychology, 5, 21-45.

Steinberg, L. (1990). Autonomy, conflict, and harmony in the family relationship. In S. Feldman \& G. Elliott (Eds.), At the threshold: The developing adolescent (pp. 255276). Cambridge, MA: Harvard University Press.

Watzlawick, P., Beavin, J., \& Johnson, D. (1967). Pragmatics of human communication: A study of interactional patterns, pathologies, and paradoxes. New York: Norton.

Xia, Y., Lin, S., Xie, X. L., Zhou, Z., \& DeFrain, J. (1998). One child family policy in China and its impact on Chinese parents' perception of children's values. Presentation at National Conference on Family Relations Annual Meeting, Milwaukee, WI. 
Xu, Z., Shen, J. X., Wan, C. W., Li, C. M., Mussen, P., \& Cao, Z. F. (1991). Family socialization and children's behavior and personality development in China. Journal of Genetic Psychology, 152(2), 239-253.

Yau, J., \& Smetana, J. G. (1996). Adolescent-parent conflict among Chinese adolescents in Hong Kong. Child Development, 67, 1262-1275.

Youniss, J., \& Smollar, J. (1985). Adolescent relations with mothers, fathers, and friends. Chicago: University of Chicago Press. 